\title{
Factors affecting adherence to national malaria treatment guidelines in management of malaria among public healthcare workers in Kamuli District, Uganda
}

\author{
Charles Bawate ${ }^{1,2,4^{*}} \mathbb{D}$, Sylvia T. Callender-Carter ${ }^{4}$, Ben Nsajju ${ }^{4}$ and Denis Bwayo ${ }^{3}$
}

\begin{abstract}
Background: Malaria remains a major public health threat accounting for $30.4 \%$ of disease morbidity in outpatient clinic visits across all age groups in Uganda. Consequently, malaria control remains a major public health priority in endemic countries such as Uganda. Experiences from other countries in Africa that revised their malaria case management suggest that health workers adherence may be problematic.
\end{abstract}

Methods: A descriptive, cross-sectional design was used and collected information on health system, health workers and patients. Using log-binomial regression model, adjusted prevalence risk ratios (PRRs) and their associated $95 \%$ confidence intervals were determined in line with adherence to new treatment guidelines of parasitological diagnosis and prompt treatment with artemisinin combination therapy (ACT).

Results: Nine health centres, 24 health workers and 240 patient consultations were evaluated. Overall adherence to national malaria treatment guidelines (NMTG) was $50.6 \%$ (122/241). It was significantly high at HC III [115 (53\%)] than at HC IV (29\%) [PRR = 0.28 (95\% Cl 0.148 0.52), p = 0.000]. Compared to the nursing aide, the adherence level was 1.57 times higher among enrolled nurses $(p=0.004)$ and 1.68 times higher among nursing officers, $p=0.238$, with statistical significance among the former. No attendance of facility malaria-specific continuing medical education (CME) sessions [PRR $=1.9(95 \% \mathrm{Cl} 1.292 .78), \mathrm{p}=0.001]$ and no display of malaria treatment job aides in consultation rooms [PRR $=0.64$ (95\% Cl 0.41 .03 ), $p=0.07$ ] was associated with increased adherence to guidelines with the former showing a statistical significance and the association of the latter borderline statistical significance. The adherence was higher when the laboratory was functional $[P R R=0.47(95 \% \mathrm{Cl} 0.350 .63)$ ] when the laboratory was functional in previous 6 months. Age of health worker, duration of employment, supervision, educational level, and age of patient were found not associated with adherence to new treatment guidelines.

Conclusion: Adherence to malaria treatment guidelines in Uganda is sub-optimal. There is an urgent need for deliberate interventions to improve adherence to these guidelines. Possible interventions to be explored should include: provision of job aides and improved access to laboratory services. There is also a need for continuous medical educational sessions for health workers, especially those at higher-level facilities and higher cadres, on adherence to guidelines in management of fever, including management of other causes of fever.

Keywords: Adherence, National malaria treatment guidelines, Uganda

*Correspondence: charlesbawate@yahoo.com

1 Kamuli District Local Government, Kamuli, Uganda

Full list of author information is available at the end of the article 


\section{Background}

The World Health Organization (WHO) estimated that there were 214 million cases of malaria in 2015 and 438,000 deaths mostly young children in sub-Saharan Africa [1]. On the African continent, at least 12 billion US dollars are spent in malaria costs of illness, treatment and premature death [2]. A prompt and accurate diagnosis of malaria is the key to effective management of malaria [3-6]. Effective case management of malaria is a major strategy that has been adopted by several countries. It entails proper clinical assessment, laboratory confirmation of the disease either by light microscopy or rapid diagnostic test (RDT) prior to treatment with an effective anti-malarial [1, 4]. In Uganda, malaria remains the leading cause of morbidity (30.4\%) and mortality (12.8\%) in its hospitals [7], with an estimated 12 million clinical cases treated annually in the public health system alone [3]. Clinical diagnosis, using fever as the major symptom, is the most widely used approach by practitioners at all levels of training. This approach has been practice in Uganda for a long time [8]. Moreover, a large number of outpatients do not have malaria parasitaemia. This creates a diagnostic dilemma and reduces the accuracy of this criterion for diagnosis of malaria [5]. The Uganda Ministry of Health $(\mathrm{MOH})$ recommends the WHO parasitological confirmation of malaria either by microscopy or RDT before initiation of treatment as per the national malaria treatment guidelines (NMTG) [5, 6].

Of all malaria-endemic countries in Africa, Uganda ranked third with an average of $30 \%$ of all outpatient department (OPD) clinic visits due to malaria (with most diagnoses made clinically) and with between 20 and $50 \%$ of all hospital admissions a consequence of malaria [9]. These admissions are due to late presentation, inadequate management and unavailability or stock-outs of effective drugs [8]. This high burden may be partly a result of misdiagnosis, since many facilities lack laboratory capacity and it is often difficult to clinically distinguish malaria from other infectious diseases. However, malaria remains responsible for a high proportion of public health expenditure on curative treatment, and efforts to reduce malaria incidence would free up available health resources and facilities and health workers' time to tackle other health issues. Experiences from other countries in sub-Saharan Africa that revised their malaria case management to artemisinin combination therapy (ACT) suggest that health workers' adherence may be problematic [10-14]. In Kenya, 3 years after the implementation of a protocol stipulating routine malaria microscopy or RDT testing of all adults presenting with fever and prescription of artemether/lumefantrine (AL) to only those who test positive, the testing rates in health facilities with diagnostic malaria services available did not exceed $54 \%$ and nearly a third of test negative cases were prescribed AL [15]. Although a Ugandan study showed use of ACT prevailing over non-recommended therapy, the quality of case management of malaria was not optimal [15]. However, in another review it was noted that health workers' adherence to revised anti-malarial prescription protocols generally improves over time [16]. Low laboratory staff numbers, non-use of standard treatment guidelines, delay in producing laboratory results, and belief that patients with negative malaria results improved upon treatment with anti-malarials, were some of the factors responsible for low adherence to laboratory results $[17$, 18].

In Uganda, clinical diagnosis using fever as the major symptom is the most widely used approach by practitioners at all levels of training. Despite fever being a major symptom of malaria, it can occur in other illnesses as well. This creates a diagnostic dilemma and reduces the accuracy of this criterion for diagnosis of malaria $[3,5]$. Effective translation of new guidelines into clinical practice is of critical importance to maximize the potential of improved, efficacious therapy and curtail the cost of malaria health care. Despite changes in policy recommendations and reported benefits, reports indicate varying levels of healthcare workers' adherence to new malaria management guidelines [10-19]. This study was conducted to determine levels of adherence to the national guidelines in the management of uncomplicated malaria in a rural district in Uganda and explore possible reasons for health workers' adherence or non-adherence.

\section{Methods \\ Definitions}

The study definitions reflected national malaria case management guidelines from the latest Uganda National Malaria Control Programme [3, 6]. In summary, the guidelines recommend parasitological confirmation of malaria either by microscopy or malaria RDT before initiation of treatment among patients presenting with fever or history of fever across all age groups. Adherence to guidelines meant that a patient suspected of malaria had: (i) a blood smear or malaria RDT done; (ii) if tested positive, s/he was prescribed only a recommended antimalarial; and, (iii) if negative, s/he was not given any antimalarial at all. Non-adherence to guidelines meant that a patient suspected of malaria had: (i) a blood test to confirm malaria was not done; (ii) a blood test was negative but $\mathrm{s}$ /he was still prescribed an anti-malarial; and, (iii) a blood test was positive but no anti-malarial or an incorrect anti-malarial, such as chloroquine was prescribed. A health centre $(\mathrm{HC})$ IV or health sub-district is the level of service delivery at county level serving a population of 100,000 people. It offers preventive, curative and 
rehabilitative care in its catchment areas. It is the second level referral service for life-saving medical, surgical and obstetric care and provision of the physical base of the health sub-districts (HSD) management team. Health centre III offers services at sub-county level for a population of about 20,000, and includes continuous preventive, promotive and curative care services and supervises $\mathrm{HC}$ II facilities under its jurisdiction [20].

\section{Study area and design}

A descriptive, cross-sectional research design was employed during December 2014. Pre-testing of the semi-structured questionnaire was done outside the facilities studied. Cronbach alpha coefficient was used to ensure internal consistency of the research tool. Individual patient records and prescription were collected and results were linked to the healthcare provider through special identifier codes. Healthcare workers who were attending to inpatients and maternity clinics were not involved in this study. Patients who had come for follow-up visits for chronic conditions such as tuberculosis and diabetes, traumas, burns, and patients referred or admitted for hospitalization were not part of the study. Collected data included demographics, presenting complaint, presumptive diagnosis, laboratory test results, drugs prescribed, and presence of job aides. Other facility and health worker-related data captured were presence of anti-malarial drugs (ACT) in facility stores, supervision reports, malaria-specific refresher training attended, and satisfaction level of patients. Nine public health facilities (eight HCIIIs and one HC IV) in Kamuli District, Uganda were studied. The names of all HC III and IV public facilities were written on small pieces of paper which were then folded and put in an empty box. Nine facilities were then drawn out of the possible 12 by simple random sampling. Each time a facility was picked, the paper was not replaced. The facilities were drawn from three HSDs, namely Buzaaya, Bugabula North and Bugabula South in Kamuli. The facilities were selected based on the following criteria: (i) availability of laboratory facility for malaria diagnosis (malaria microscopy or RDT performance); and, (ii) had to be level III or IV.

At the facility, three health workers were randomly selected among those found on duty. Twenty-seven patients were systematically sampled out at outpatient department at exit per facility. Observations were conducted at exit to minimize Hawthorne effect. A first case was identified at exit and then every third person who met the criteria was enrolled in the study. In case anyone declined, the immediate next person would be approached. The process continued until the number of 27 patients was reached. These patients were identified within 1-2 days depending on how busy the facilities were.

Kamuli District is located in southeastern Uganda. The climate is typically tropical with two distinct seasons.

\section{Data management and statistical analyses}

Completed questionnaires once reviewed at the end of the day were filed for data entry. Data entry was designed in Epi-data version 3.1 with in-built checks and double-entry to minimize data-entry errors. Data were entered and secured on a password-protected computer. Data were transferred from Epi-data to Stata ${ }^{\circledR}$ version 11(StataCorp, College Station, TX, USA) software for statistical analyses. Exploratory analyses were done to check for cleanliness and any outliers, or erroneous-looking data were cross-checked and cleaned where errors were identified.

Prevalence risk ratios (PRRs) were used as a measure of association because the outcome (adherence to guidelines) was high [16]. For multivariate analysis binomial regression models were used to determine the adjusted PRRs and their associated $95 \%$ confidence intervals. Multivariable models were adjusted for potential confounders, which were added if they showed statistical significance of 0.10 or less at bivariate analysis, and other factors were added to the model if they had been found to be significantly associated with adherence to these guidelines in related studies.

\section{Ethical approval}

Ethical approval for this study was received from the Bugema University School of Graduate Studies Ethical Review Board and Kamuli District local government also provided clearance.

\section{Results}

\section{Characteristics of study respondents}

Nine health centres were visited during the study time (eight HC III and one HC IV). The mean age and median for health workers were 33.32 and 34 years, respectively. There were an equal number (12) of health workers by gender. Majority of the health workers had formal healthrelated education level with only two $(8.3 \%)$ not having formal medical training. A total of 240 patient records were reviewed at exit with 88 (36.7 \%) of the patients being children under 5 years of age and 159 (66.25\%) were female (Table 1).

\section{Adherence to national malaria treatment guidelines}

The overall prevalence of adherence to guidelines was $50.6 \%(122 / 241)$. The adherence to guidelines was $76.14 \%$ among those who were tested and found 
Table 1 Characteristics of study respondents

\begin{tabular}{|c|c|c|c|}
\hline \multirow[t]{2}{*}{ Variable } & \multirow[t]{2}{*}{ Total N (\%) } & \multicolumn{2}{|l|}{ Facility level } \\
\hline & & 8 HC III N (\%) & 1 HC IV N (\%) \\
\hline \multicolumn{4}{|l|}{ Healthcare workers } \\
\hline \multicolumn{4}{|l|}{ Age } \\
\hline Mean (SD) & $33.32(7.97)$ & & \\
\hline Median (Range) & $34(30)$ & & \\
\hline \multicolumn{4}{|l|}{ Gender of respondents } \\
\hline Male & 12 & $11(91.67)$ & $1(8.33)$ \\
\hline Female & 12 & $10(83.33)$ & $2(16.67)$ \\
\hline \multicolumn{4}{|l|}{ Educational level } \\
\hline No formal education & 2 & $2(100.0)$ & $0(0.0)$ \\
\hline Certificate holder & 13 & $11(84.62)$ & $2(15.38)$ \\
\hline Diploma holder & 9 & $8(88.89)$ & $1(11.11)$ \\
\hline \multicolumn{4}{|l|}{ Patients } \\
\hline \multicolumn{4}{|l|}{ Age } \\
\hline Under 5 years & 88 & $85(96.59)$ & $3(3.41)$ \\
\hline Over 5 years & 152 & $130(85.53)$ & $22(14.47)$ \\
\hline \multicolumn{4}{|l|}{ Gender } \\
\hline Male & 81 & $78(96.3)$ & $3(3.7)$ \\
\hline Female & 159 & $137(86.16)$ & $22(13.84)$ \\
\hline
\end{tabular}

negative. Only $42.97 \%$ of those who tested positive were managed according to policy guidelines. All patients who did not access laboratory services were managed contrary to new policy guidelines (Table 2).

Adherence to NMTG was significantly higher at HC III [115 (53 \%)] than at HC IV (29\%) [adjusted PRR $=0.28$ (95\% CI 0.1480 .52 ), $\mathrm{p}=0.000]$. Compared to the nursing aides, the adherence level was 1.57 times higher among enrolled nurses $(p=0.004)$ and 1.68 times higher among nursing officers, $\mathrm{p}=0.238$ with statistical significance among the former. Non-attendance of facility

Table 2 Adherence to national malaria treatment guidelines

\begin{tabular}{lcll}
\hline Variable & $\begin{array}{l}\text { Adhered } \\
\text { to guidelines } \\
\mathbf{N}(\%)\end{array}$ & $\begin{array}{l}\text { Did not adhere } \\
\text { to guidelines } \\
\mathbf{N}(\%)\end{array}$ & P value \\
\hline $\begin{array}{l}\text { Adherence level } \\
\text { All }\end{array}$ & $122(50.62)$ & $119(49.38)$ & \\
$\begin{array}{l}\text { Facility level } \\
\text { HC III }\end{array}$ & $115(53.0)$ & $102(47.0)$ & \\
HC IV & $7(29.17)$ & $17(70.83)$ & 0.027 \\
Laboratory findings & & $73(57.03)$ & \\
Malaria positive & $55(42.97)$ & $21(23.86)$ & \\
Malaria negative & $67(76.14)$ & $25(100)$ & \\
No laboratory findings & $0(0)$ &
\end{tabular}

continuing medical education (CME) session on malaria [adjusted PRR $=1.9$ (95\% CI 1.292 .78$), \mathrm{p}=0.001$ ] and no display of malaria treatment job aides in consultation rooms [adjusted PRR $=0.64$ (95\% CI 0.41 .03 ), $\mathrm{p}=0.07$ ] were associated with increased adherence to guidelines with the former showing a statistical significance and the association of the latter borderline statistical significance. Presence of a functional laboratory was found to be associated with adherence to the guidelines. The adjusted PRRs were 0.47 (95\% CI 0.35 0.63) when the laboratory was functional in previous 6 months. The following factors were found not to be associated with adherence to guidelines in this study: age of health worker, educational level of health worker and age of patient (Table 3).

\section{Diagnosis}

The commonest malaria diagnostic technique is malaria RDT (90.87\%).

"We have RDTs, microscopy but we always use RDTs here because of the ease of use."-(Key informant)

"Malaria RDT have been very helpful, they have saved us from having stock-outs of anti-malarials; previously before RDT, in most cases we were treating malaria based on clinical features yet there are other problems which present with same symptoms and signs. It is not common to have stock-out these days because we give anti-malarial to patients following the laboratory investigations."-(Key informant) (Table 4).

\section{Prescription pattern}

Of the 128 patients who had malaria confirmed present, $55(42.97 \%)$ were treated with an appropriate ACT. Seventy-two $(56.25 \%)$ of the same category of people were prescribed both an anti-malarial and at least an antibiotic. Prescription of non-ACT anti-malarials was low at only $3.5 \%$ of all those prescribed anti-malarials. Out of the 88 patients who were parasitologically established to be malaria negative, 21 (23.86 \%) were prescribed antimalarial drugs. Nearly all those who presented with fever but had no laboratory tests done were prescribed antimalarial drugs and/or antibiotics.

Healthcare workers said non-reliability of laboratories (25.27\%), delay in producing laboratory results (12.37\%), presence of cardinal malaria signs $(26.34 \%)$, presence of a "typical" clinical picture of malaria (8.06\%), and presence of signs and symptoms of malaria with no suspicion of any other differential diagnosis (27.96 \%) being the drivers for not basing malaria management according to laboratory findings (Table 5). 
Table 3 Prevalence, unadjusted and adjusted prevalence risk ratios (PRRs) of factors associated with adherence to national malaria treatment guidelines among health workers in Kamuli District, Uganda

\begin{tabular}{|c|c|c|c|c|c|}
\hline Characteristic & Adhered N (\%) & Unadjusted PRRs (95 \% Cl) & $P$ value & Adjusted PRRs (95 \% Cl) & $P$ value \\
\hline All & $122 / 241(50.6)$ & & & & \\
\hline \multicolumn{6}{|c|}{ Age of health worker (years) } \\
\hline $21-30$ & $60(53.6)$ & 1 & & - & \\
\hline $31-40$ & $40(46.5)$ & $1.04(0.741 .47)$ & 0.79 & - & \\
\hline$>40$ & $22(51.6)$ & $0.91(0.631 .32)$ & 0.61 & - & \\
\hline \multicolumn{6}{|l|}{ Facility level } \\
\hline $\mathrm{HC} I I$ & $115(53)$ & 1 & & 1 & \\
\hline HC IV & $7(29)$ & $0.55(0.291 .04)$ & 0.06 & $0.28(0.1480 .52)$ & 0.000 \\
\hline \multicolumn{6}{|l|}{ Gender of health worker } \\
\hline Male & $49(40.1)$ & 1 & & - & \\
\hline Female & $73(59.8)$ & $0.87(0.681 .12)$ & 0.29 & - & \\
\hline \multicolumn{6}{|c|}{ Highest educational level } \\
\hline Below certificate & $11(55)$ & 1 & & - & \\
\hline Certificate & $56(57.1)$ & $1.03(0.671 .6)$ & 0.86 & - & \\
\hline Diploma & $55(45.1)$ & $0.82(0.531 .27)$ & 0.38 & - & \\
\hline \multicolumn{6}{|c|}{ Category of health worker } \\
\hline Nurse aide & $11(55)$ & 1 & & 1 & \\
\hline Enrolled nurse & $50(55.6)$ & $0.91(0.641 .29)$ & 0.62 & $1.57(1.41 .75)$ & 0.004 \\
\hline Nursing officer & $13(52.0)$ & $0.85(0.531 .38)$ & 0.53 & $1.68(1.352 .20)$ & 0.238 \\
\hline Clinical officer & $42(42.9)$ & $0.71(0.481 .02)$ & 0.38 & $1.16(0.761 .76)$ & 0.48 \\
\hline \multicolumn{6}{|c|}{ Refresher training in last 2 years } \\
\hline Yes & $76(62.3)$ & 1 & & - & \\
\hline No & $46(37.7)$ & $1.07(0.831 .38)$ & 0.59 & - & \\
\hline \multicolumn{6}{|c|}{ Attended facility CME on malaria in last year } \\
\hline Yes & $105(49.3)$ & 1 & & 1 & \\
\hline No & $5(25.0)$ & $1.52(1.142 .02)$ & 0.004 & $1.9(1.292 .78)$ & 0.001 \\
\hline \multicolumn{6}{|c|}{ Malaria treatment job aides displayed in consultation room } \\
\hline Yes & $105(49.3)$ & 1 & & 1 & \\
\hline No & $5(25.0)$ & $1.52(1.142 .02)$ & 0.004 & $0.64(0.41 .03)$ & 0.07 \\
\hline \multicolumn{6}{|c|}{ Laboratory functionality in last 6 months } \\
\hline All days of week & $75(56.8)$ & 1 & & 1 & \\
\hline Only on week days & $38(40.4)$ & $0.71(0.530 .95)$ & 0.02 & $0.47(0.350 .63)$ & 0.000 \\
\hline Rarely open & $9(60.0)$ & $1.06(0.681 .63)$ & 0.08 & $0.63(0.410 .97)$ & 0.037 \\
\hline \multicolumn{6}{|c|}{ Facility supervised in last 6 months } \\
\hline Supervised by DHT & $91(46.1)$ & 1 & & & \\
\hline Supervised by HSD & $14(82.6)$ & $1.76(1.342 .29)$ & 0.000 & - & \\
\hline Supervised by $\mathrm{MoH}$ & $6(75.0)$ & $1.6(1.042 .45)$ & 0.031 & - & \\
\hline \multicolumn{6}{|c|}{ Facility had anti-malarial stock-out in last 3 months } \\
\hline Yes & $30(41.7)$ & 1 & & 1 & \\
\hline No & $92(54.4)$ & 1.31 (1.06 1.77) & 0.0000 & 1.17 (0.79 1.72) & 0.43 \\
\hline \multicolumn{6}{|l|}{ Age of patient } \\
\hline$<5$ years & $43(49.3)$ & 1 & & 1 & \\
\hline$\geq 5$ years & $79(51.3)$ & $1.03(0.798345$ 1.34) & 0.08 & 1.07 (0.83 1.39) & 0.543 \\
\hline
\end{tabular}

\section{Discussion}

The study aimed to assess clinician, health system and patient factors affecting adherence to guidelines in management of malaria among public healthcare workers.
The results provide some explanations to help understand where possible interventions could improve the level of adherence to national guidelines. Adherence to the national guidelines is quite low at just above $50.6 \%$. 
Table 4 Laboratory diagnostic services

\begin{tabular}{lcc}
\hline Variable & Frequency (N) & Percentage (\%) \\
\hline Common diagnostic method & & \\
Malaria RDT & 219 & 90.87 \\
Microscopy & 20 & 8.3 \\
Both microscopy and malaria RDT & 2 & 0.83 \\
Laboratory diagnostic method used & & \\
Malaria RDT & 219 & 90.87 \\
Both microscopy and malaria RDT & 1 & 0.41 \\
Do not know (not indicated) & 21 & 8.71 \\
\end{tabular}

Table 5 Reasons some health workers gave for not basing prescription on laboratory results

\begin{tabular}{lll}
\hline Variable & Frequency (N) & Percentage (\%) \\
\hline Laboratory not reliable & 47 & 25.27 \\
Delay in producing laboratory results & 23 & 12.37 \\
Presence of cardinal malaria signs & 49 & 26.34 \\
$\begin{array}{l}\text { Presence of a "typical" clinical picture } \\
\text { of malaria }\end{array}$ & 15 & 8.06 \\
$\begin{array}{l}\text { Presence of signs and symptoms of } \\
\text { malaria with no suspicion of any }\end{array}$ & 52 & 27.96 \\
$\quad$ other differential diagnosis & & \\
\hline
\end{tabular}

Despite availability of clear guidelines and supervision, health workers do not follow recommended guidelines because of health system and health worker-related reasons. The factors associated with adherence to guidelines were: level of facility, cadre of health worker, presence of job aides in consultation rooms, recent attendance of a CME session on malaria and presence of a functional laboratory.

Better adherence to guidelines was more common practice at lower-level facilities. Related to this was the finding that lower-level cadres, such as nurses and nurse aides, adhered to guidelines better than higher-level cadres, such as clinical officers. This finding was similar to that observed in many other African countries where ACT was introduced [11-15, 17-19, 21, 23]. A study in Kenya by Zurovac et al. showed that nursing aides complied more closely to treatment guidelines than clinical officers [15]. Previous Ugandan studies have shown similar findings with most showing better adherence by clinical officers and nurses than doctors, who are considered better trained [16, 17, 21]. Possible explanations for this could be that higher level trained workers such as medical officers and clinical officers believe they have higher medical acumen and hence a tendency not to use the guidelines. Indeed, many of the clinical officers interviewed reported that their reasons for not adhering to these guidelines were because either the laboratory was not reliable or they could rely on presence of "typical" malaria signs to make a decision.

It could also be that higher-level cadres tend to be in administrative positions and are often missed out for supervision and training. This could be reflective of the pre-service training gaps that include non-alignment of medical school curriculum to national standards.

Unlike most of the previous studies in Uganda and the rest of Africa, this study found presence of job aides and recent participation in a facility-based medical education session was associated with improved adherence to guidelines. This could be explained by there being an ongoing project supporting the district to improve its capacity to manage malaria. As part of the project, infacility education sessions were conducted and RDTs supplied. It will be interesting to re-assess this after the end of the project.

Thirdly, awareness by clinicians that there was a functional laboratory on most days was associated with better adherence to guidelines. This has not been explored by most of the other studies on this subject [11-19]. Many health workers who did not adhere to guidelines reported that this was because of the delay in getting results from the laboratory. It appears that the key factor in improving diagnostics for malaria was the introduction of RDTs as the vast majority of tests were done with RDTs. Others have shown the availability of RDTs improved malaria case management $[21,23,24]$. Widespread provision of malaria RDTs could well play a significant role in reducing the persistent problem of malaria overdiagnosis and contribute to reduced risk of malaria under-treatment. This is more so in a setting in the most affected parts of the world where microscopic diagnosis is hampered by unavailability of microscopes and electricity.

An important key finding was that prescription of ACT when a malaria diagnosis was made was almost universal with only about $5 \%$ not prescribing ACT. This is a much higher rate than that seen in previous Ugandan studies [18, 19, 21, 23, 25]. This could have been affected by local factors such as limited ACT stocks, ongoing malaria project in the district, and the fact that this was limited to the public sector. Private facilities have been known to be more likely to prescribe nonACT. This study was limited to the public sector unlike 
other studies that have included some private sector facilities [24, 25].

This study highlights the significant shortage of human resources in rural districts. More than $60 \%$ of the patients were attended to by nurses and nursing aides. This, despite the fact that nursing aides are not expected to be managing patients according to current health guidelines in Uganda [20].

The lack of association of age of health worker, duration of employment, supervision, educational level and age of patient, in-service training is consistent with the majority of other studies on this subject [11-19, 22, 23, 26].

\section{Limitations}

This study had a number of limitations. First, the study was conducted in public health facilities; this limits generalizability to these facilities. Second, it was conducted in one district in which there was an ongoing project addressing malaria management. This might not be replicated in other districts without such support. Third, despite targeting clients at exit, the study results might have been subject to bias from the Hawthorne effect, since the health workers were aware that their facilities and actions were being observed. The study did not assess impact of patient demands and the study was conducted over a short period of time. Additionally $\mathrm{HC}$ IIs were not studied yet they do manage malaria cases. This limits generalizability of findings to all levels of the healthcare system.

\section{Conclusions}

This study found that health worker case management decisions were associated with health system and health worker-related factors that are potentially modifiable. Although some recent evidence suggests that use of text message reminders to health workers might improve provider behaviours at low cost, evidence-based interventions to improve rural health worker adherence to management guidelines are generally lacking or show mixed results [26-28]. This study strengthens the case for provision of aides, targeted, facility-based, continuing medical education on malaria, and targeting higher level, trained, health cadres. Another key issue is the need to ensure laboratories or at the very least RDT testing services are readily available to reduce waste of resources due to over-diagnosis [29-31]. Given the lack of good evidence on what works, interventional studies to evaluate the impact of these approaches is required to provide definitive guidance on what interventions best translate into better malaria treatment practices in Uganda.

\section{Authors' contributions}

$\mathrm{CB}$ and $\mathrm{DB}$ conceived the idea. All contributed to data collection. $\mathrm{CB}$ and $\mathrm{DB}$ led the analysis and interpretation of the data. CB, DB, STCC, and BN wrote the first draft of the paper. All authors reviewed and approved the final draft of the paper prior to submission. All authors read and approved the final manuscript.

\section{Author details}

${ }^{1}$ Kamuli District Local Government, Kamuli, Uganda. ${ }^{2}$ BLC Research Centre Iganga, Uganda. ${ }^{3}$ Civil Society Fund, Kampala, Uganda. ${ }^{4}$ Department of Public Health, Bugema University, Kampala, Uganda.

\section{Acknowledgements}

We thank the hard-working staff and study respondents at the study centres. We thank the Bugema University School of Graduate Studies; Dr Paul Katamba, Stephen Kizza, Associate Professor Nazarius M Tumwesigye, and Kamuli District authorities. We thank Abunyanga Odeke Stephen, Moses Tenyhwa, Lydia Mukisa, Agnes Tibenda, and Livingstone Kyakulaga for their work during the initial preparation and formulation of the study.

The study was approved by Bugema School of Graduate Studies and Kamuli District Health authorities prior to study initiation. Consent was obtained from all study participants. Confidentiality was ensured through use of study numbers instead of respondents' names. Prior to study initiation, three research assistants were first trained in data collection techniques, rapport and accurate recording of data on the various research tools for the study. The study researchers were responsible for the quality of questionnaires and data collected

Competing interests

The authors declare that they have no competing interests. 


\section{Appendix 1}

See Table 6.

Table 6 Health Centers and Health worker sampling frame: Population of Kamuli Health Care workers per station

\begin{tabular}{|c|c|c|c|c|c|c|c|c|}
\hline No & Institution & $\begin{array}{l}\text { Medical } \\
\text { officers }\end{array}$ & $\begin{array}{l}\text { Clinical } \\
\text { officers }\end{array}$ & $\begin{array}{l}\text { Nursing } \\
\text { officers }\end{array}$ & $\begin{array}{l}\text { Enrolled } \\
\text { nurses }\end{array}$ & $\begin{array}{l}\text { Enrolled } \\
\text { midwives }\end{array}$ & $\begin{array}{l}\text { Nursing } \\
\text { assistant }\end{array}$ & Total \\
\hline 1 & DHO office & 1 & 0 & 1 & 0 & 0 & 0 & 2 \\
\hline 2 & Kamuli General Hospital & 4 & 9 & 20 & 25 & 18 & 15 & 91 \\
\hline $3^{*}$ & Balawoli HC III & 0 & 2 & 1 & 2 & 3 & 1 & 9 \\
\hline $4^{*}$ & Namasagali HC III & 0 & 2 & 2 & 2 & 3 & 2 & 11 \\
\hline $5^{*}$ & Nabirumba HC III & 0 & 2 & 1 & 2 & 3 & 1 & 9 \\
\hline 6 & Namaira HC II & 0 & 0 & 0 & 0 & 1 & 1 & 2 \\
\hline 7 & Kibuye HC II & 0 & 0 & 1 & 0 & 1 & 0 & 2 \\
\hline 8 & Kiige HC ॥ & 0 & 0 & 0 & 2 & 0 & 0 & 2 \\
\hline 9 & Kawaga HC II & 0 & 0 & 0 & 1 & 0 & 0 & 1 \\
\hline 10 & Kasolwe HC II & 0 & 0 & 0 & 0 & 3 & 0 & 3 \\
\hline 11 & Kamuli youth centre $\mathrm{HC} \|$ & & 0 & 0 & 1 & 1 & 0 & 2 \\
\hline 12 & Nawankofu HC II & 0 & 0 & 0 & 0 & 1 & 1 & 2 \\
\hline 13 & Kagumba HC II & 0 & 0 & 0 & 0 & 1 & 1 & 2 \\
\hline 14 & Namunyingi HC II & 0 & 0 & 0 & 1 & 2 & 1 & 4 \\
\hline $15^{*}$ & Nankandulo HC IV & 1 & 4 & 3 & 5 & 3 & 2 & 18 \\
\hline $16^{*}$ & Mbulamuti HC III & 0 & 3 & 1 & 4 & 2 & 3 & 13 \\
\hline $17^{*}$ & Lulyambuzi HC III & 0 & 2 & 1 & 2 & 4 & 1 & 10 \\
\hline $18^{*}$ & Bupadhengo HC III & 0 & 2 & 1 & 2 & 2 & 2 & 9 \\
\hline $19^{*}$ & Bugulumbya HC III & 0 & 3 & 3 & 1 & 2 & 1 & 10 \\
\hline 20 & Buluya HC II & 0 & 0 & 1 & 0 & 1 & 1 & 3 \\
\hline 21 & Kiyunga HC II & 0 & 0 & 0 & 1 & 0 & 1 & 2 \\
\hline 22 & Nawandyo HC II & 0 & 0 & 0 & 1 & 1 & 1 & 3 \\
\hline 23 & Kasambira HC II & 0 & 0 & 1 & 0 & 0 & 1 & 2 \\
\hline 24 & Nawantumbi HC II & 0 & 0 & 1 & 0 & 1 & 1 & 3 \\
\hline 25 & Buwoya HC II & 0 & 0 & 0 & 0 & 1 & 1 & 2 \\
\hline 26 & Bubago HC II & 0 & 0 & 0 & 1 & 1 & 0 & 2 \\
\hline 27 & Luzinga HC II & 0 & 0 & 0 & 0 & 0 & 1 & 1 \\
\hline 28 & Kiyunga-Bukakanda HC II & & 0 & 1 & 0 & 0 & 0 & 1 \\
\hline $29^{*}$ & Namwendwa HCIV & 2 & 3 & 3 & 3 & 3 & 2 & 16 \\
\hline $30^{*}$ & Butansi HC III & 0 & 2 & 1 & 2 & 3 & 1 & 9 \\
\hline $31^{*}$ & Kitayunjwa HC III & 0 & 2 & 3 & 2 & 2 & 2 & 11 \\
\hline $32^{*}$ & Bulopa HC III & 0 & 2 & 1 & 2 & 3 & 1 & 9 \\
\hline 33 & Kinu HC II & 0 & 0 & 0 & 1 & 1 & 0 & 2 \\
\hline 34 & Kyeeya HC II & 0 & 0 & 0 & 1 & 1 & 0 & 2 \\
\hline 35 & Nabirama HC II & 0 & 0 & 1 & 1 & 0 & 1 & 3 \\
\hline 36 & Kinawampere $\mathrm{HC} \|$ & 0 & 0 & 0 & 1 & 0 & 1 & 2 \\
\hline \multirow[t]{2}{*}{37} & Busota HC II & 0 & 0 & 0 & 0 & 1 & 1 & 2 \\
\hline & Total & 8 & 38 & 48 & 66 & 69 & 48 & 277 \\
\hline
\end{tabular}

* Facilities sampled 


\section{Appendix 2}

See Fig. 1.

\section{Map of Kamuli District}

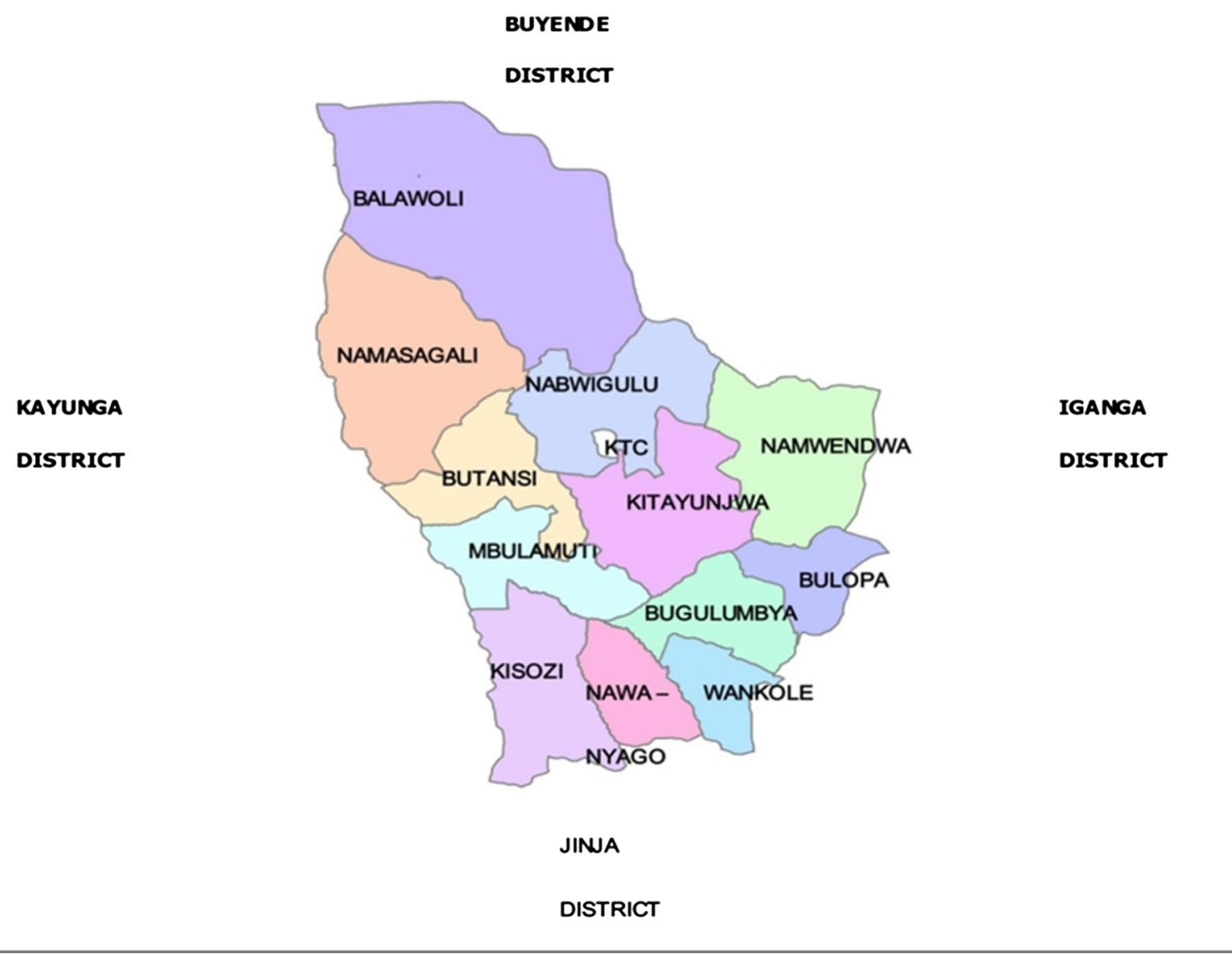

Fig. 1 Map showing Kamuli District. It lies at an average altitude of $1083 \mathrm{~m}$ above sea level and extends $00-56^{\prime}$ North/330-05' East up to 010-20' North/330-15' East. It has a total land area of $1622 \mathrm{~km}^{2}$ and $62.64 \mathrm{~km}^{2}$ (3.9\%) of water. The District is among the most underdeveloped and poor in Uganda (Ministry of finance, planning and economic development (MOFPED), 2003)

Received: 8 November 2015 Accepted: 6 February 2016

Published online: 24 February 2016

\section{References}

1. WHO. World Malaria Report. Geneva: World Health Organization. 2015.

2. Centers for Disease Control and Prevention. Centers for Disease Control and Prevention Malaria Program. Center for Global Health; 2010. http:// www.cdc.gov/malaria. Accessed on 3 Apr 2014

3. Republic of Uganda. The Uganda Malaria Reduction Strategic Plan 2014-2020: Malaria Control Programme, Ministry of Health; 2015.

4. Ministry of Health. National policy on malaria treatment. Uganda: Kampala; 2006.

5. Republic of Uganda. Uganda Clinical Guidelines. Kampala: National guidelines on management of common conditions. Ministry of Health; 2010
6. Republic of Uganda. Uganda clinical guidelines. Kampala: National guidelines on management of common conditions. Ministry of Health; 2012.

7. Republic of Uganda. Annual Health Sector Performance Report. 2013/2014. Kampala: Ministry of Health. 2014

8. Nankabirwa J, Zurovac D, Njogu NJ, Rwakimari BJ, Counihan H, Snow RW, et al. Malaria misdiagnosis in Uganda-implications for policy change. Malar J. 2009;8:66. doi:10.1186/1475-2875-8-66.

9. Uganda Bureau of Statistics (UBOS) and ICF International. Uganda Malaria Indicator Survey 2014-15. Kampala, Uganda, and Rockville, Maryland, USA: UBOS and ICF International. 2015.

10. Pulford J, Mueller I, Siba MP, Hetzel WM. Malaria case management in Papua New Guinea prior to the introduction of a revised treatment protocol. Malar J. 2012;11:157. doi:10.1186/1475-2875-11-157.

11. Selemani M, Masanja Ml, Kajungu D, Amuri M, Njozi M, Khatib AR, et al. Health worker factors associated with prescribing of artemisinin combination therapy for uncomplicated malaria in rural Tanzania. Malar J. 2013:12:334. doi:10.1186/1475-2875-12-334. 
12. Steinhardt $C L$, Chinkhumba J, Wolkon A, Luka M, Luhanga M, Sande $J$, et al. Patient, health worker and health facility level determinants of correct malaria case management at publicly funded health facilities in Malawi: results from a nationally representative health facility survey. Malar J. 2014;13:64.

13. Zurovac D, Njogu J, Akhwale W, Hamer HD, Snow WR. Translation of artemether-lumefantrine treatment policy into paediatric clinical practice: an early experience from Kenya. Trop Med Int Health. 2008;13:99107. doi:10.1111/j.1365-3156.2007.01980.

14. Juma E, Zurovac D. Changes in health workers' malaria diagnosis and treatment practices in Kenya. Malar J. 2011;10:1.

15. Zurovac D, Rowe A, Ochola S, Midia B, English M, Snow RW. Predictors of the quality of health worker treatment practices for uncomplicated malaria at government health facilities in Kenya. Int J Epidemiol. 2004;33:1080-91.

16. Axelson O, Fredrikson M, Ekberg K. Use of the prevalence ratio Vs the prevalence odds ratio as a measure of risk in cross sectional studies. Occup Environ Med. 1994;51:574.

17. Hensen B, Paintain LS, Shretta R, Bruce J, Jones C, Webster J. Taking stock: provider prescribing practices in the presence and absence of ACT stock. Malar J. 2011;10:218

18. Nanyingi M. Adherence to laboratory findings in the management of malaria in the high and low transmission areas of Nakasongola and Kabalore Districts of Uganda. Health Policy Dev. 2008;6:164-72.

19. Sears D, Kigozi R, Mpimbaza A, Kakeeto S, Sserwanga A, Staedke GS, et al. Anti-malarial prescription practices among outpatients with laboratory-confirmed malaria in the setting of a health facility-based sentinel site surveillance system in Uganda. Malar J. 2013;12:252. doi:10.1186/1475-2875-12-252.

20. Ministry of Health. Health Sector Strategic Plan III. 2010/11-2014/15. Government of Uganda, Kampala.

21. Zurovac D, Tibenderana KJ, Nankabirwa J, Ssekitooleko J, Njogu NJ, et al. Malaria case-management under artemether-lumefantrine treatment policy in Uganda. 2008. Malar J. 2008;7:181. doi:10.1186/1475-2875-7-181.

22. Chanda P, Hamainza B, Moonga BH, Chalwe V, Banda P, Pagnoni F. Relative costs and effectiveness of treating uncomplicated malaria in two rural districts in Zambia: implications for nationwide scale-up of home-based management. Malar J. 2011;10:159.

23. Njama D, Tamala M, Clark D, Nzarubara B, Staedke S, Kamya MR, et al. Treatment of malaria restricted to laboratory confirmed cases: a prospective cohort study in Ugandan children. Malar J. 2007;6:7.

24. Udoh E, Oyo-ita A, Odey F, Effa E, Esu E, Oduwole O, et al. Management of uncomplicated malaria in underfives in private and public health facilities in South-Eastern Nigeria: a clinical audit of current practices. Malar Res Treat. 2013;2013:575080

25. Meremikwu M, Okomo U, Nwachukwu C, Oyo-Ita A, Eke-Njoku J, Okebe J, et al. Anti-malarial drug prescribing practice in private and public health facilities in south-east Nigeria: a descriptive study. Malar J. 2007;6:55.

26. Ngasala EB. Improved malaria case management in under-fives in the era of artemisinin-based combination therapy in Tanzania. PhD Thesis, Unit of Infectious Diseases, Department of Medicine Karolinska University Hospital, Karolinska Institutet, Stockholm, Sweden. 2010.

27. Rowe AK, de Savigny D, Lanata CF, Victora CG. How can we achieve and maintain high-quality performance of health workers in low-resource settings? Lancet. 2005;366:1026-35.

28. Zurovac D, Sudoi RK, Akhwale WS, Ndiritu M, Hamer DH, Rowe AK, et al. The effect of mobile phone text-message reminders on Kenyan health workers' adherence to malaria treatment guidelines: a cluster randomised trial. Lancet. 2011;378:795-803.

29. WHO. Promoting access to and rational use of artemisinin-based combination therapy in the private sector. Geneva: World Health Organization. 2005.

30. Batwala V, Magnussen P, Hansen KS, Nuwaha F. Cost-effectiveness of malaria microscopy and rapid diagnostic tests versus presumptive diagnosis: implications for malaria control in Uganda. Malar J. 2011;10:372 (Published online 19 Dec 2011).

31. Lubell Y, Reyburn H, Mbakilwa H, Mwangi R, Chonya K, Whitty MJC, Mills A. The cost-effectiveness of parasitologic diagnosis for malariasuspected patients in an era of combination therapy. Am J Trop Med Hyg. 2007;77:128-32

\section{Submit your next manuscript to BioMed Central and we will help you at every step:}

- We accept pre-submission inquiries

- Our selector tool helps you to find the most relevant journal

- We provide round the clock customer support

- Convenient online submission

- Thorough peer review

- Inclusion in PubMed and all major indexing services

- Maximum visibility for your research

Submit your manuscript at www.biomedcentral.com/submit
C Biomed Central 